\title{
Gauntlet Fisheries for Elasmobranchs - the Secret of Sustainable Shark Fisheries
}

\author{
Jeremy D. Prince \\ Biospherics P/L, P. O. Box 168, South Fremantle WA, 6162 Australia
}

Prince, J. D. 2005. Gauntlet Fisheries for Elasmobranchs - the Secret of Sustainable Shark Fisheries. J. Northw. Atl. Fish. Sci., 35: 407-416. doi:10.2960/J.v35.m520

\begin{abstract}
The longevity and low fecundity of sharks make them particularly vulnerable to over-exploitation. Previous studies have emphasized the range of natural productivities observed across elasmobranch species and have used this to explain the sustainability of some elasmobranch fisheries and the depletion of others. This paper discusses the assessment of the two principal species fished by the Southern Shark Fishery of Australia, school shark (Galeorhinus galeus) and gummy shark (Mustelus antarcticus). The modeled simulations presented here show that shark behaviour patterns and fishing techniques which restrict fishing mortality to a few juvenile age-classes may be equally or more important than the productivity of different species in determining their relative robustness under exploitation. Counterintuitively concentrating a fishery on a few year-classes of pups, juveniles or sub-adults proves to be a robust management strategy for elasmobranch fisheries, as long as the means exist for protecting adults from fishing mortality. Furthermore this management strategy proves to be most effective with the species considered to be least productive, those with greatest longevity. The obverse of this finding is to highlight the damaging impact on elasmobranch fisheries of human activities such as by-catch, finning, sport fishing and beach protection that cause even low levels of adult mortality.
\end{abstract}

Key words: Australia, elasmobranch, Galeorhinus galeus, juveniles, management, mortality, Mustelus antarcticus, shark fishery, sustainable

\section{Introduction}

It has long been recognized that the longevity and low fecundity of sharks makes them particularly vulnerable to over-exploitation. This led Holden (1973) to question whether any elasmobranch fishery could be sustainable? The answer Holden supplied to his own rhetorical question was a provisional 'yes' provided there was "caution because so much depends on the biology of the species exploited". Stevens et al. (1997) and Walker (1998) elaborated on this question and answered by detailing the range of natural productivity (fecundity, longevity and growth rates) observed amongst exploited elasmobranch species and highlighting the need to sustainably match exploitation levels to the productivity of each species.

This paper discusses the assessment of the two principal species fished by the Southern Shark Fishery (SSF) of Australia, school shark (Galeorhinus galeus) and gummy shark (Mustelus antarcticus). It presents modeling results which show that other patterns of behaviour and interactions with fisheries which restrict fishing to a few age-classes may be equally or more important in determining the relative robustness of different species under exploitation.

\section{School shark}

School shark are a widely distributed Charcharhinid. They are an active coastal-pelagic shark found in tem- perate and insular waters north and south of the equator. They feed on shoaling prey along the continental shelf and slope in 0-500 m (Olsen, 1954). Olsen (1954) documented 500-2 $500 \mathrm{~km}$ movements in southern Australia but in Australia it was generally assumed to mainly be demersal (Blaber and Bulman, 1987). However recent archival tagging studies suggest a semi-pelagic, vertically migrating species that may spend some time in an oceanic environment (Stevens et al., 1997).

As first described by Olsen (1954) and highlighted by Stevens et al. (1997) and Walker (1998) the school shark has a low level of natural productivity $(M=0.1)$. In Southeast Australia their longevity has been demonstrated by the recapture of tagged individuals after 36 and 42 years at liberty (Olsen, 1990). First maturity is observed around 8-10 years of age but full fecundity of around 25 pups per cycle is not attained until about 13 years old and litters are apparently produced on average every third year.

School shark also aggregate throughout their life cycle to breed and feed, and can be profitably fished during all stages of their life by knowledgeable fishers, even at low population levels. Olsen (1959) described the fishing targeted at each stage of their life cycle. Pupping females and pups were fished over summer in certain sheltered marine embayments and estuaries that constituted the pupping and nursery grounds. Sub-adults were fished along the continental shelf while they aggregated to feed 
on shoaling prey species. The adults were also targeted in feeding aggregations at the shelf break, and also during winter while participating in mating aggregations that form along the slope.

Olsen (1959) concluded that, "the school shark fishery, which is operating on a single stock of sharks with a slow growth rate, a late sexual maturity, and a low fecundity, shows trends which are suggestive of depletion. The decline is believed to be due not only to a too intensive offshore fishery, but also to the resultant reduced recruitment and depressed reproductive potential caused by the earlier destruction of juveniles and pregnant females."

In the light of these life history characteristics it surprises no one that the fishery has declined wherever it is fished with any intensity. Together with the Californian Soupfin Shark and North Atlantic Porbeagle fishery, the collapse of the Australian school shark fishery has been laid down as the classic proof of the vulnerability of shark stocks (Olsen, 1959).

The puzzling aspect of the Australian school shark fishery has actually been the surprising durability of the fishery. Following Olsen's diagnosis the fishery contracted during the 1950s and 1960s. But successive re-expansion of the fishery and peaks in landings occurred in the late1960s and 1980s (Fig. 1 and 2a). It appears (Punt et al., 2000) that the spatial complexity referred to by Walker (1998) has sustained production from this fishery. The fishery for this wide-ranging species has displayed a sequential pattern of expansion and depletion as the fishery

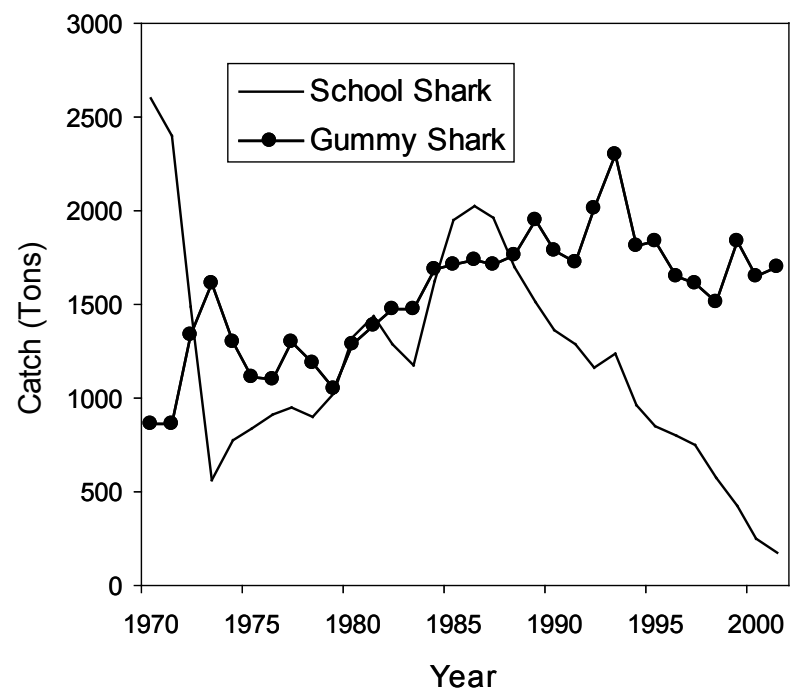

Fig. 1. SSF catch (tons) of school and gummy shark 1970-2001. expanded into new fishing grounds further and further away from the central markets.

Pupping grounds are probably more widespread across the fishery than originally understood and pregnant females may exhibit philopatry returning to natal pupping grounds. Thus while mixing as sub-adults and adults on feeding grounds at the shelf-edge and beyond, the stocks may remain structured because females return to natal pupping grounds. As suggested by Gary Sharpe, Centre for Climate/Ocean Resources Study, Monterey, California (unpubl. report) school shark stocks are probably structured by processes that include "a long, slow interchange of breeding adults across the entire habitat
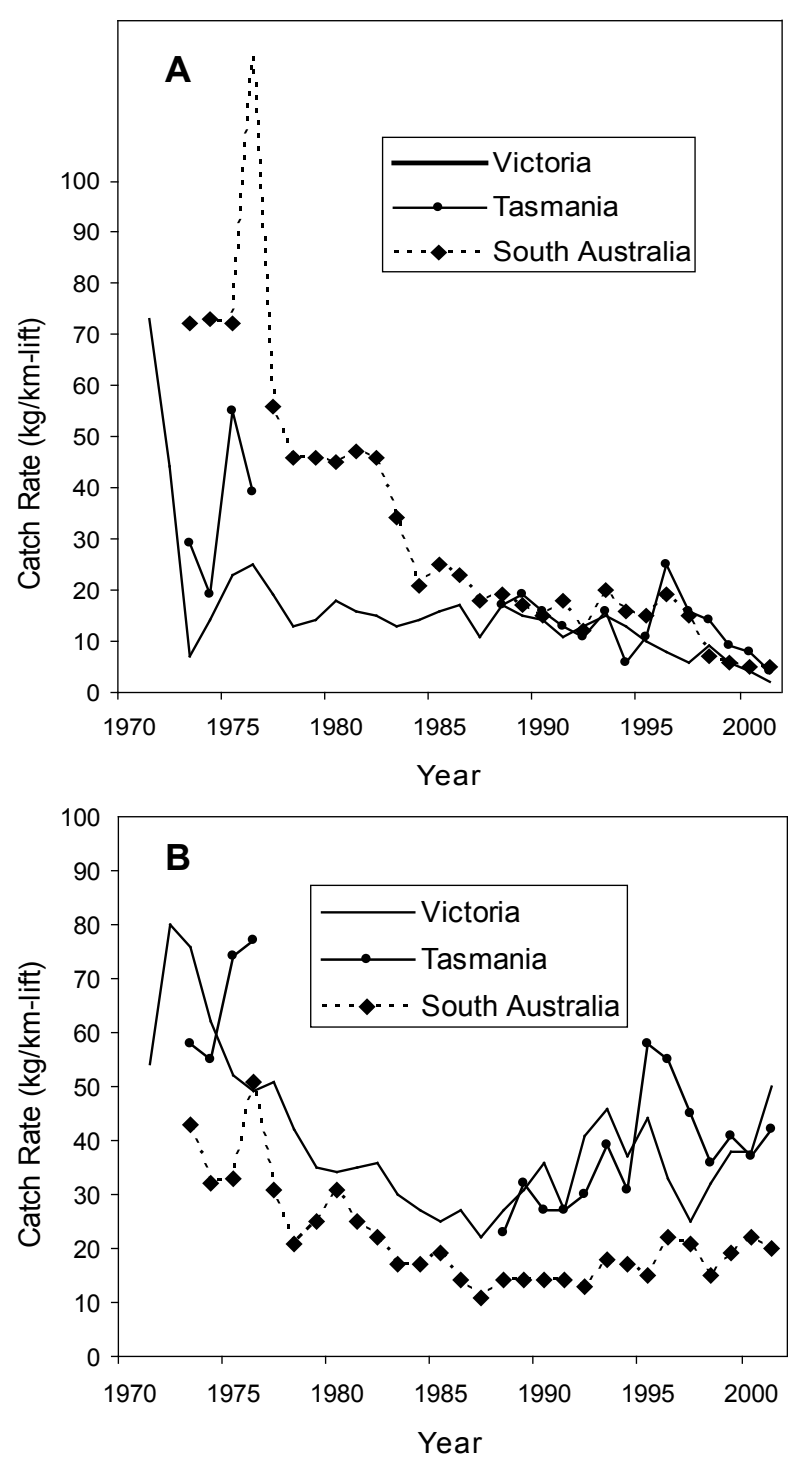

Fig. 2. SSF catch rates $(\mathrm{kg} / \mathrm{km}$-lift) by state during 1970-2001 for (A) school shark and (B) gummy shark. 

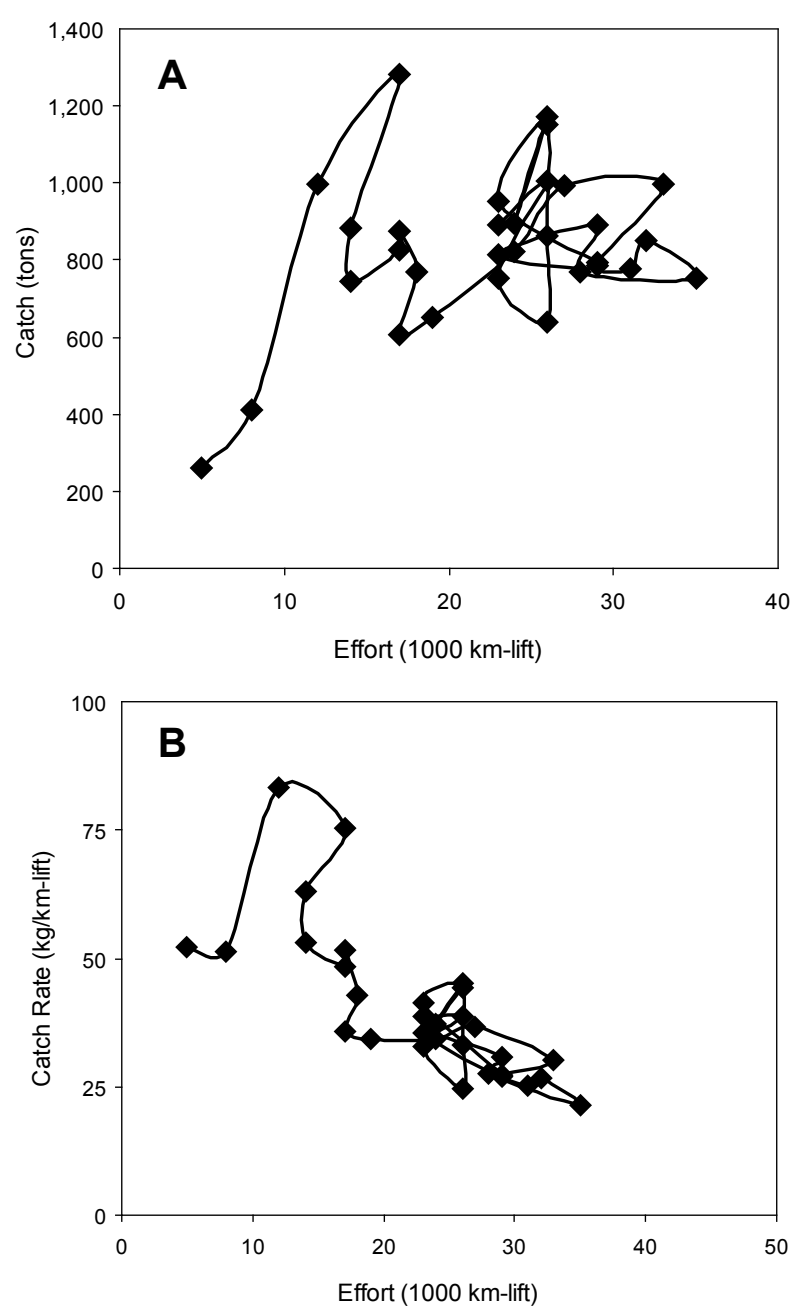

Fig. 3. (A) Victorian gummy shark catch (tons) $v s$ effort (1 $000 \mathrm{~km}$-lift) and (B) Victorian gummy shark catch rate $(\mathrm{kg} / \mathrm{km}$-lift $) v s$ effort (1 $000 \mathrm{~km}-$ lift $)$ during 1970-2001.

that precludes isolation yet does not overwhelm the local or regional uniqueness."

The fishery has apparently sustained itself by expanding unsustainably into new territory with relative lightly fished stocks, leaving behind heavily exploited areas with depleted endogenous breeding stocks but which continue to receive ongoing low levels of recruitment through the immigration of mobile feeding sharks from other areas. Following the decline of the school shark fishery in each area the fishery has switched to fishing less profitably but evidently more sustainably gummy shark.

\section{Gummy Shark}

By contrast to school shark, the gummy shark is relatively sedentary and demersal. It is also relatively unspecialized in its utilization of the habitat. The ac- counts of fishers in Bass Strait and some data suggest there may be specific mating grounds. But there are apparently no specialized pupping grounds, newly birthed pups are found throughout the $0-150 \mathrm{~m}$ depth band of the continental shelf they inhabit. There is a small fishery for gummy shark in the bays and estuaries but approximately $90 \%$ of the catch comes from aggregations of sub-adults and maturing animals in $25-50 \mathrm{~m}$.

As noted by Stevens et al. (1997) and Walker (1998), gummy shark are naturally more productive than school shark. Gummy shark have a higher rate of natural mortality $(M=0.188)$ implying a longevity of around 16 years. Breeding begins between 3-8 year of age and adult fecundity is $20-50$ pups each $1-2$ years. So as concluded by those authors it is not surprising that the fishery for this species has been more robust than for school shark. Currently it is assessed to be relatively lightly fished (Punt et al., 2001).

However, a notable dynamic of this fishery is the stability of catches over a wide range of effort levels since the mid-1980s (Fig. 1). As fishing effort first expanded and then contracted under pro-active management, catch rates, which halved from 1970 to 1985 have been substantially rebuilt by 2000 (Fig. 2b). Viewed from a different perspective, the data from just the state of Victoria show the amazing stability of catch over time and a three-fold range of effort levels (Fig. 3a) making catch-rate principally a function of effort (Fig. 3b).

Assessment models have trouble explaining why catches do not increase at higher effort levels. This dynamic is currently modeled as increasing gear competition at high effort levels, although even with this model catches should be more responsive to effort than is actually observed.

As modeled by Walker (1998) the robust nature of this fishery is largely due to density dependent factors, which are assumed to impact the rate of natural mortality throughout the life span of the gummy shark. Thus increased survival of $0-2$ year-old animals is assumed to have offset the falling number of births as parental biomass has fallen to about $50 \%$ of initial levels while maintaining a relatively constant recruitment of 2-year-old animals has been maintained as parental biomass has fallen to about $50 \%$ of inital levels.

\section{Gauntlet Fishery}

Prince (1992) drew attention to the uniform size distribution of the catch and proposed that the behaviour of gummy shark affected availability of the stock to fishing creating a "gauntlet fishery" which principally fishes 2-4 
year old sub-adult and maturing age-classes. Stevens et al. (1997) emphasized the effect of mesh selectivity on the catch; noting that the relatively small mesh size used in this fishery combined with the blunt head of the gummy shark results in the increased escapement of the more fecund larger animals.

But there are grounds for believing that additional factors make the adult stock of this species relatively invulnerable to fishing pressure. Punt (2000) used data collected from surveys during 1986-87 and 1998 to address the question of "whether length frequency distributions for gummy shark from "aggregated" shots are tighter than those from "background" shots and to assess the availability function for gummy sharks in "aggregation" relative to those in the "background scatter". The results support the hypothesis that high catch rate ("aggregated") shots lead to tighter length-frequency distributions. The availability function based on the survey data shows a similar pattern to that derived from the assessment although the latter is tighter."

Punt et al. (2001) concluded that availability and selectivity play a role in maintaining the population under exploitation. "The result that the population is estimated to be currently more than $70 \%$ of its virgin size is a direct consequence of the estimated availability and selectivity patterns. These imply that only a relatively small fraction of the population is vulnerable to the fishery at any one time. The selectivity patterns (used in the assessment model) are based on experimental results (e.g. Kirkwood and Walker, 1986), while the parameters that determine availability as a function of length are estimated as part of the model-fitting procedure. Independent analysis of survey data for gummy shark (Punt, 2000) also indicated that availability should not be assumed to be uniform."

Based on personal observation of commercial fishing, the cursory examination of stomach contents in the commercial catch, interviews with experienced fishers, and analysis of the fisheries dynamics, it can be hypothesized that gummy shark become available at commercial catch rates in certain areas, when sub-adult and maturing shark feed bentho-pelagically on swarms of pelagically feeding prey. While the species is widely distributed along the continental shelf the fishery concentrates on the same relatively small areas, approximately $60 \%$ of the catch comes from just $12 \%$ of the area inhabited by the stock. When fishers search for commercial catch rates, the size structure of the catch is such as would be expected from the documented selectivity of the gill nets being used. However when the high catch rates are found and commercial catch rates are achieved the size structure changes and is more restricted than predicted by mesh selectivity alone. The enhanced catchability at these times probably results from the younger and more agile sharks swimming energetically off the bottom to chase squid (Loliginidae), swimmer crabs (Portunidae) and mantid shrimp (Stomapoda), before coasting back towards the bottom (Walker et al. 1989). It is probably this energetic lifting off and returning to the bottom that temporarily increases their catchability in bottom set gillnets to commercial levels. Presumably this chasing down of small pelagic prey is energetically inefficient for larger age classes of gummy shark, as larger demersal invertebrates such as octopus (Octapodidae), lobster (Palinuridae and Scyllaridae) and decorator crabs (Majidae) become increasingly important in their diet with increasing size (Walker et al. 1989).

Whatever the underlying causes of this dynamic, the effect in the fishery is to concentrate fishing pressure on a relatively few sub-adult age-classes. Outside of the bays and inlets the gummy shark breeding stock is hardly fished because densities are so low that fishing for them is uneconomic. In effect the species grows through a gauntlet of fishing and upon gaining maturity is relatively protected from fishing.

Simpfendorfer (1999) has described a similar dynamic in the dusky whaler fishery off southwestern Australia. The dusky whaler, Carcharhinus obscurus (Lesueur, 1818), is a widely distributed large aggressive pelagically feeding species with a typical elasmobranch life history. Off southwestern Australia, regulated mesh size of gillnets ensures the fishery principally captures neonates (age 0 ) with some juveniles (1-4 years old). Historically fishing mortality on adults has been zero. Simpfendorfer (1999) concluded that, "one possible strategy for the sustainable exploitation of long-lived, late-maturing, slow-growing, slow-reproducing marine species is to target exploitation at the youngest age-classes."

The notion that concentrating fishing on pups and sub-adults can promote sustainability is in many ways counter-intuitive. This sentiment is embodied in a comment passed by Gary Sharpe, Centre for Climate/Ocean Resources Study, Monterey, California (unpubl. data); "the suggestion that the fishery be targeted at younger age-classes flies in the face of everything we have learned about slow growing, small litter-size animals. You must target the least productive sectors, when they are not involved in procreation, not rapidly growing, next generations, or they will fail to generate a next generation."

\section{Testing Hypotheses}

The interest in this study is to demonstrate and describe the "gauntlet effect" which evidently has played some role in making these stocks robust under exploitation. Of particular interest is the magnitude of the "gauntlet 
effect" in relation to the different productivity of these species. Using a modeling based approach, stocks of gummy and school shark with their differing levels of productivity have been exploited with alternative fishing regimes so that the effect of the gauntlet style of fishery and the effect of differing productivity levels can be compared.

\section{Methods}

\section{Description of the Analysis}

In this analysis the fishery dynamics of school and gummy shark are modeled as examples of low and high productivity species, respectively. These two species have been used to:

- compare the effect of a range of fishing mortalities (F) under either gauntlet fishing or fishing the entire $\geq 2+$ population, and

- explore the relative effect of differing rates of natural productivity.

\section{Description of the Model}

The model has been implemented in a simple Excel framework; it is an age-structured model, which works entirely in numbers of individuals within each year-class and year.

The parameter values assumed for the present analysis are the same as those used by the Shark Fishery Assessment Group in its most recent assessments of the fishery. For school shark they follow those used as the base case by Punt and Walker (1998) and for gummy shark they have been drawn from the base case analysis by Punt et al. (2001).

For both species the number of individuals $(N)$ of any age $\geq 2$ years is the number of animals the year before, times survival (s) from natural mortality $(M)$ times survival from fishing mortality $(F)$ :

$$
N_{a, t}=N_{a-1, t-1} s\left(1-M_{t-1}\right) s\left(1-F_{t-1}\right)
$$

Natural mortality of the gummy shark is assumed to be 0.188 , and for school shark 0.10 . A range of exploitation pressures were modeled for both species.

\section{Gummy Shark Recruitment}

Recruitment to the $0+$ age-class of any year was based on the number of adults in the previous year, half of which were assumed to be female and 0.66 of which are expected to breed in any year.

The relationship between female body length and number of pups in a litter was:

$$
P_{a}=e^{(a+b)}
$$

where $a$ and $b$ are -1.852 and 0.0032 , respectively ( $L_{a}$ up to $1800 \mathrm{~mm}$ and maximum litter size of 50). Together with an age-length key derived from the von Bertalanffy curve described by the parameters:

$$
\begin{aligned}
& L_{\infty}=2019 \mathrm{~mm} \\
& k=0.123 \\
& t_{0}=-1.55
\end{aligned}
$$

The relationship was used to derive the number of pups produced by pupping females of each age-class up to age 30 (Table 1).

\section{School Shark Recruitment}

\begin{tabular}{|c|c|c|c|c|}
\hline $\begin{array}{c}\text { Age } \\
\text { (years) }\end{array}$ & $\begin{array}{c}\text { School } \\
\text { shark } \\
\text { length } \\
(\mathrm{mm})\end{array}$ & $\begin{array}{c}\text { School } \\
\text { shark } \\
\text { pups per } \\
\text { litter }\end{array}$ & $\begin{array}{l}\text { Gummy } \\
\text { shark } \\
\text { length } \\
(\mathrm{mm})\end{array}$ & $\begin{array}{c}\text { Gummy } \\
\text { shark } \\
\text { pups per } \\
\text { litter }\end{array}$ \\
\hline 1 & 495 & - & 544 & - \\
\hline 2 & 661 & - & 714 & - \\
\hline 3 & 802 & - & 865 & - \\
\hline 4 & 923 & - & 999 & 4 \\
\hline 5 & 1026 & - & 1117 & 6 \\
\hline 6 & 1113 & - & 1221 & 8 \\
\hline 7 & 1188 & - & 1314 & 11 \\
\hline 8 & 1252 & - & 1395 & 14 \\
\hline 9 & 1306 & 18 & 1467 & 17 \\
\hline 10 & 1352 & 20 & 1531 & 21 \\
\hline 11 & 1391 & 22 & 1588 & 25 \\
\hline 12 & 1425 & 24 & 1638 & 30 \\
\hline 13 & 1454 & 25 & 1682 & 34 \\
\hline 14 & 1478 & 25 & 1721 & 39 \\
\hline 15 & 1499 & 25 & 1755 & 43 \\
\hline 16 & 1516 & 25 & 1786 & 48 \\
\hline 17 & 1531 & 25 & 1813 & 50 \\
\hline 18 & 1544 & 25 & 1837 & 50 \\
\hline 19 & 1555 & 25 & 1858 & 50 \\
\hline 20 & 1565 & 25 & 1876 & 50 \\
\hline 21 & 1572 & 25 & 1893 & 50 \\
\hline 22 & 1579 & 25 & 1908 & 50 \\
\hline 23 & 1585 & 25 & 1920 & 50 \\
\hline 24 & 1590 & 25 & 1932 & 50 \\
\hline 25 & 1594 & 25 & 1942 & 50 \\
\hline 26 & 1598 & 25 & 1951 & 50 \\
\hline 27 & 1601 & 25 & 1959 & 50 \\
\hline 28 & 1603 & 25 & 1966 & 50 \\
\hline 29 & 1606 & 25 & 1972 & 50 \\
\hline 30 & 1607 & 25 & 1977 & 50 \\
\hline
\end{tabular}

Recruitment to the 0+ age-class of any year was based on the number of adults in the previous year, 0.5

TABLE 1. School and gummy shark age keys for length and number of pups per litter. 
of which were assumed to be female, and 0.333 of which are expected to breed in any year.

The relationship between female body length $\left(L_{a}\right.$ $1300-1400 \mathrm{~mm}$ and maximum litter size of 25) and number of pups $\left(P_{a}\right)$ was:

$$
P_{a}=a+b L_{a}
$$

where $a$ and $b$ are -42.93 and 0.0468 , respectively. This has been used together with an age-length key derived from the von Bertalanffy curve described by the parameters:

$$
\begin{aligned}
& L_{\infty}=1618.3 \mathrm{~mm} \\
& k=0.16 \\
& t_{0}=-1.28
\end{aligned}
$$

to derive the number of pups produced by pupping female of each age-class (Table 1). Punt and Walker (1998) also incorporate a decline in proportion pupping at smaller sizes. For ease of programming this was not followed here.

\section{Density Dependence}

Density dependence for both species is assumed to work on the $0+$ and $1+$ year-classes with their natural survival $\left(S_{0-1}\right)$ being proportional to the size of $\geq 2+$ population $\left(D_{t}\right)$ in the previous year, relative to an assumed carrying capacity $D_{0}=100000$ individuals.

\section{Results}

The assumed mechanism of density dependence causes some early population oscillations in the modeled scenarios (Fig. 4-7) as juvenile survival increases when the virgin population structure is fished. Similarly when assumptions about natural mortality rates are changed the assumed mechanism of density dependence causes the size of the modeled population at equilibrium to either rise or fall (Fig. 6-7). The dynamics of these density dependence effects are peripheral to the following analysis and are not discussed further.

\section{The Gauntlet Effect}

Figures $4 \mathrm{a}$ and $\mathrm{b}$ show modeled population trajectories for school shark over a range of constant exploitation rates. Figure $4 \mathrm{a}$ assumes fishing is applied to all ageclasses $\geq 2$ years old, whereas Fig. 4 b assumes a gauntlet fishery fishes only 4-6 year old animals. Figures $5 \mathrm{a}$ and $\mathrm{b}$ show the equivalent modeled trajectories for the gummy shark population.

The primary objective of this modeling exercise is to clearly demonstrate that for both species, the gauntlet fishery is far more robust to fishing, sustaining double the fishing mortality $(F)$ than fishing all $\geq 2$-year-old sharks.
Not as immediately obvious from these figures is the different time span over which declines occur. When the long-lived school shark breeding stock is directly targeted, population declines as large as 50\% occurred within 5-15 years of fishing (Fig. 4a). In contrast, fishing mortality of twice the intensity in the gauntlet fishery causes declines of that magnitude over 15-40 years of fishing (Fig. 4b). A similar, although less pronounced, effect is observed for gummy shark (Fig. 5a and b). It is not until the supply of maturing animals is cut off by fishing, and natural mortality kills off the breeding biomass that recruitment starts to decline. Thus stock declines in gauntlet fisheries occur over extended periods of time.

Obviously the robustness of the gauntlet fishery is due to the relative inefficiency of the fishing technique. The gauntlet fishery basically makes the older breeding stock invulnerable to fishing. It has not been modeled here but the obverse of this effect is that catch rates from the gauntlet fishery will be lower for each level of exploitation. This is borne out in reality as historically in the SSF school shark fishers searched for $1000 \mathrm{~kg} /$ day, while gummy shark fishers searched for $400 \mathrm{~kg} /$ day.

The difference between school shark and gummy shark is of interest. Note that the gauntlet effect is actually less pronounced for gummy shark than for school shark. In the school shark population where all $>2+$ age-classes are fished with $F=0.3$ the population declines to under 10000 individuals by the $15^{\text {th }}$ year of the simulation (Fig. $4 a)$. By comparison with $F=0.6$ the gauntlet fishery for school shark declined to this level over 113 years (Fig. $4 b)$. The comparison for gummy shark is the $35^{\text {th }}$ year (Fig. 5a) and $70^{\text {th }}$ year, respectively (Fig. 5b). Thus the least productive species benefits most from the gauntlet style of the fishery.

The question that then follows is what aspect of natural productivity is it that creates this effect? School shark has lower levels of mortality, fecundity and growth. Which of these contribute most to this effect? This was tested by repeating the scenarios with the school shark model using the natural mortality rate of gummy shark $(M=0.188)$, and with the gummy shark model using natural mortality rate of school shark $(M=0.1)$.

The result of these simulations are that the school shark population with $M=0.188$ and with all $>2+$ ageclasses fished with $F=0.3$ declines to under 10000 individuals after the $10^{\text {th }}$ year (Fig. 6a), whereas the equivalent gauntlet style fishery with $F=0.6$ declines to this level after the $24^{\text {th }}$ year (Fig. 6b). The higher rate of natural mortality and low fecundity of school shark combine to make the breeding biomass more susceptible 

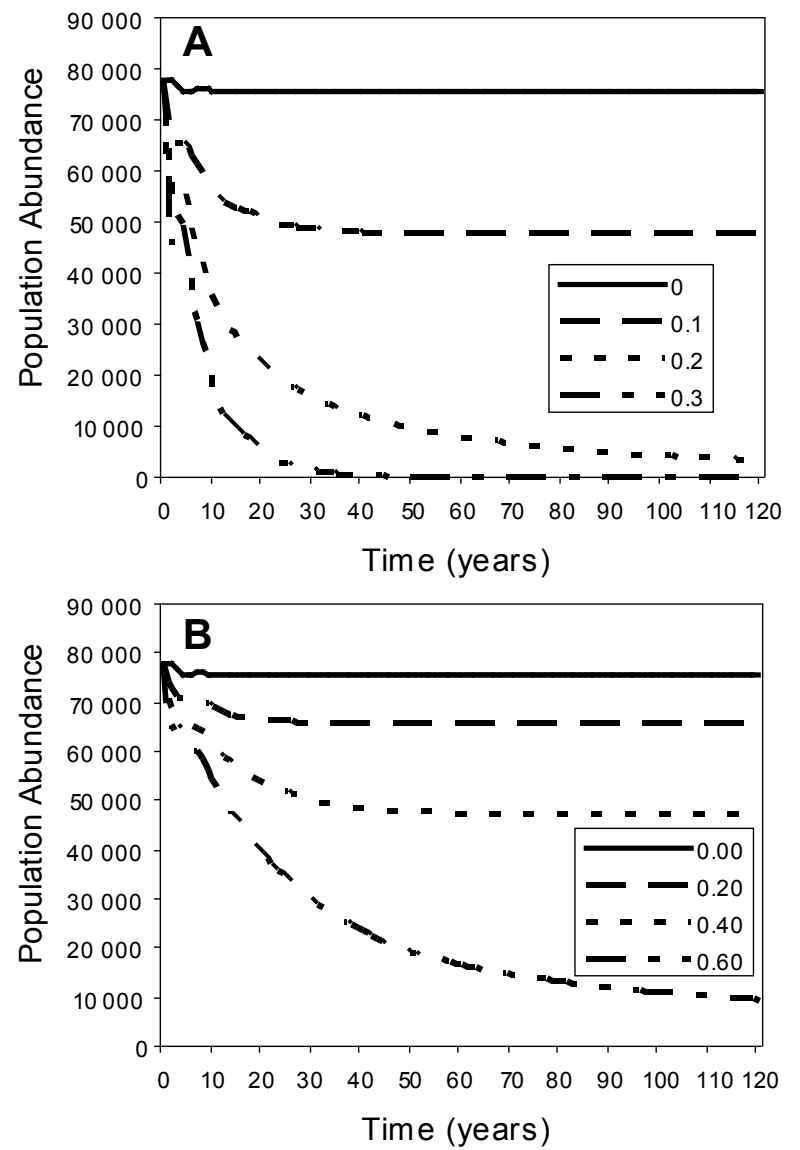

Fig. 4. (A) Modeled dynamics of a school shark stock with all $2+$ age-classes fished with a range of exploitation rates $(F=0-0.30)$ and $(\mathbf{B})$ modeled dynamics of a school shark stock with a gauntlet style of fishery fishing the 4-6+ age-classes with a range of exploitation rates $(F=0-0.60)$.

to fishing down and less amenable to being preserved by the gauntlet fishery.

In contrast, the gummy shark population with $M=0.1$ does not decline to under 10000 individuals during 120 years of simulation when all $>2+$ year-classes are fished with $F=0.3$ (Fig. 7a) or when with the gauntlet style fishery and $F=0.7$ (Fig. 7b). This increased robustness under exploitation observed with both styles of fishing is attributable to the increase in potential pup production that results from applying a lower rate of natural mortality to the higher fecundity of gummy shark. Recall that as modeled the school shark fecundity reaches a maximum of 25 pups per litter at 13 years of age, while gummy shark fecundity increases with age to a maximum of 50 pups per litter at 17 years of age. With $M=0.188$ just $4.4 \%$ of the gummy shark population can potentially survive to reach
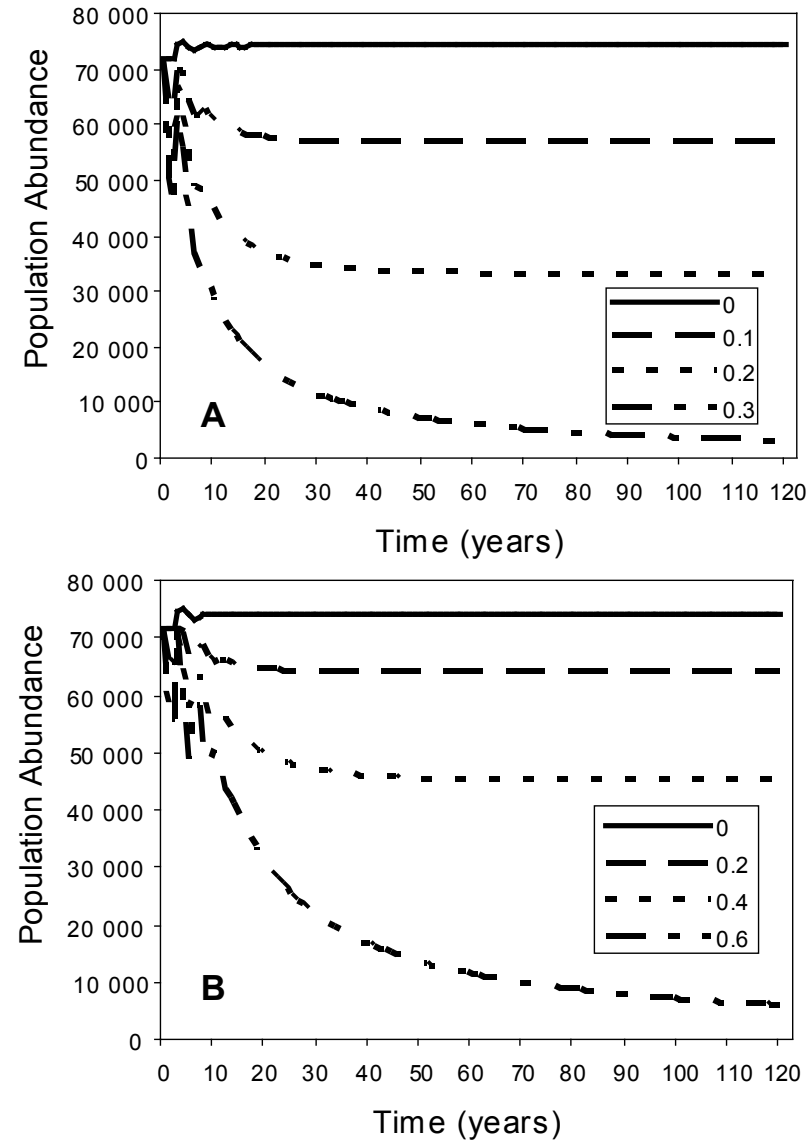

Fig. 5. (A) Modeled dynamics of a gummy shark stock with all $2+$ age-classes fished with a range of exploitation rates $(F=0-0.30)$ and (B) modeled dynamics of a gummy shark stock and a gauntlet style of fishery fishing the 4-6+ age-classes with a range of exploitation rates $(F=0-0.60)$.

peak productivity, however with $M=0.1$ this proportion increases to $20.1 \%$ a very large increase in breeding potential when the high fecundity assumed for these older animals is taken into account. Thus under both modeled fisheries the lower rate of natural mortality interacts with the higher fecundity of gummy sharks to increase the potential pup production and consequently the unfished equilibrium level of the stock (Fig. 7a and b).

To re-establish some level of equivalence, extra scenarios involving higher fishing mortalities $(F=0.8)$ were added to this model. In these scenarios, the gummy shark population with $M=0.1$ declined to $<10000$ individuals after the $22^{\text {nd }}$ year when all $\geq 2+$ age-classes were fished with $F=0.4$ (Fig. 7a), but did not decline to this level until the $44^{\text {th }}$ year under the gauntlet fishery with $F=0.8$ (Fig. 7b). 
Looking back across the various models we see that the two most robust scenarios (Fig. $4 \mathrm{~b}$ and $7 \mathrm{~b}$ ) involve the lower rate of natural mortality. Thus we conclude that the effect of the gauntlet style fishery confers most advantage on species with lower rates of natural mortality. With higher rates of natural mortality, the gauntlet effect is diminished because the breeding stock protected from fishing is eroded away more rapidly by the higher rate of natural mortality (Fig. 6b).

\section{Discussion}

This analysis strongly supports the counter-intuitive conclusion of Simpfendorfer (1999) that, "a possible
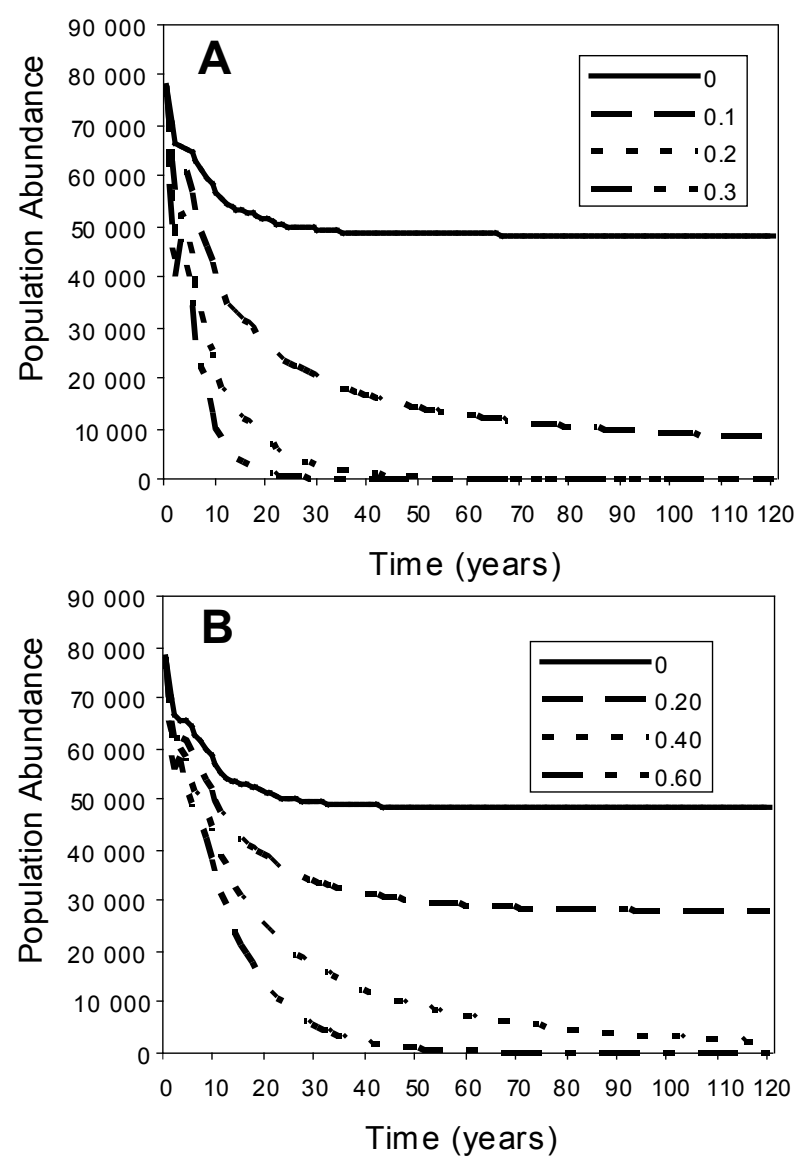

Fig. 6. (A) Modeled dynamics of a school shark stock with a gummy shark rate of natural mortality $(M=0.18)$ with all $2+$ age-classes fished with a range of exploitation rates $(F=0-0.30)(\mathbf{B})$ Modeled dynamics of a school shark stock with a gummy shark rate of natural mortality $(M=$ 0.18 ) and a gauntlet style of fishery fishing the 4-6+ age-classes with a range of exploitation rates $(F=0-0.60)$. strategy for the sustainable exploitation of long-lived, latematuring, slow-growing, slow-reproducing marine species is to target exploitation at the youngest age-classes."

This finding in no way contradicts the general realization that elasmobranch fisheries are extremely susceptible to overfishing. Rather the conclusion of this work is that a small sub-set of shark fisheries are robust to fishing pressure. As the difficulty of sustaining elasmobranch populations in the face of even low levels of fishing is increasingly realized, the global need for rapid assessment of these populations will become paramount. Shark fisheries are very important for some artisanal fishers and the task of assessing and managing shark fisheries should
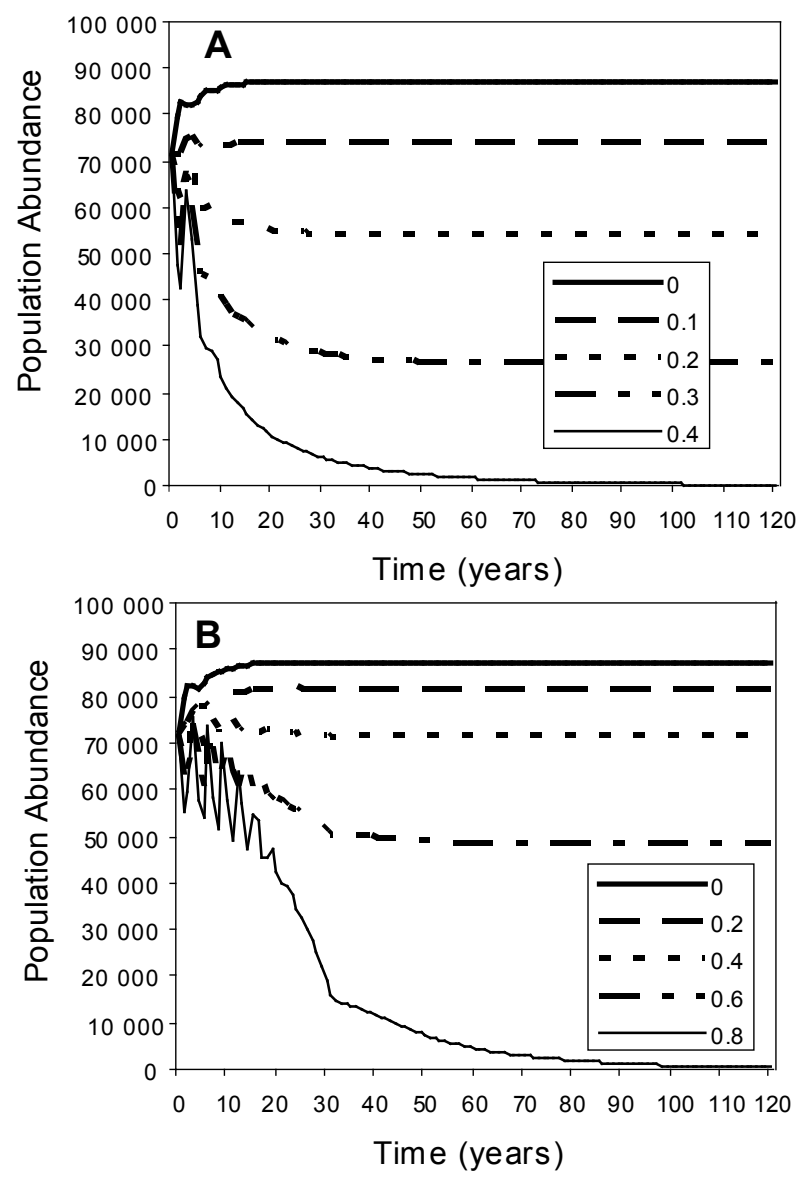

Fig. 7. (A) Modeled dynamics of a gummy shark stock with a school shark rate of natural mortality $(M$ $=0.10)$ with all $2+$ age-classes fished with a range of exploitation rates $(F=0-0.40)$ and (B) Modeled dynamics of a gummy shark stock with a school shark rate of natural mortality $(M=0.10)$ and a gauntlet style of fishery fishing the 4-6+ age-classes with a range of exploitation rates $(F$ $=0-0.80)$. 
not be made more difficult by blindly assuming all shark fisheries are extremely vulnerable to over exploitation. It is important to recognize and make allowances for what is obviously a small sub-set of robust shark fisheries.

In the process of rapid assessment, this small subset of robust shark fisheries may be recognized by the following characteristics:

- The fishery only targets several year-classes of pups, juveniles and sub-adults.

- The long-lived adults remain unfished.

- Over generations of the exploited species catches remain stable across a wide range of fishing pressure.

Shark fisheries with these characteristics may well prove to be sustainable, and management attention should not immediately focus upon closing them. Instead management attention should focus on ensuring habitat is preserved for all age-classes and that fisheries do not develop which inflict mortality upon the adults.

Of course the further implication of these results is that where there is an interest in managing a shark fishery towards sustainability the first step to be recommended $a$ priori is modifying fishing techniques so that long lived adults are protected. As discussed by Simpfendorfer (1999) "the implementation of a fishing strategy that targets the youngest age-classes is reliant on being able to catch only the desired age-classes. Two strategies can be used to achieve this:

1) The first of these is to use size-selective fishing gear. Gill nets in particular are strongly sizeselective and can be used to target a restricted number of age-classes.

2) The second strategy of targeting the youngest age-classes is to fish in areas where only the desired age-classes occur. Since many species utilize distinct nursery areas, these represent an ideal location of age-specific fishing provided that the adults are not taken."

The obverse of this finding is the widely recognized fact that even low levels of fishing mortality over a wide range of ages make this management strategy unsustainable. In the case of the Western Australian dusky whaler fishery increasing fishing pressure on adults from the increased use of baited hooks hanging off pot-ropes in the overlapping lobster fishery and a growing tuna and billfish long-line fleet are giving rise to concerns about the sustainability of this resource (Simpfendorfer, 1999). This should further focus attention on the damaging impact of activities that result in even low levels of on-going mortality on adult sharks such as by-catch, finning, liver fishing, sport fishing and beach protection programs.

\section{Acknowledgements}

My thanks go to Terry Walker and Russell Hudson of the Primary Industries Research Victoria Queenscliff Centre, Victoria, Australia, and to Rory McAuley of the Western Australia Marine Research Laboratory, Australia, for their generous support of this work with ideas, data and figures.

\section{References}

BLABER, S. J. M., and C. M. BULMAN. 1987. Diets of fishes of the upper continental slope of eastern Tasmania: content, calorific values, dietary overlap and trophic relationships. Mar. Biol., 95: 345-356.

HOLDEN, M. J. 1973. Are long-term sustainable fisheries for elasmobranchs possible? In: Fish stocks and recruitment. B. B. Parish (ed.). ICES Rapp. Proc.-Verb., 164: 360-367.

KIRKWOOD, G. P., and T. I. WALKER. 1986. Gill net mesh selectivities for gummy shark, Mustelus antarcticus Gunther, taken in south-eastern Australian waters. Aust. J. Mar. Freshw. Res., 37: 689-697.

OLSEN, A. M. 1954. The biology, migration, and growth rate of the school shark, Galeorhinus australis (Macleay) (Carcharhinidae) in south-eastern Australian waters. Aust. J. Mar. Freshw. Res., 5: 353-410.

1959. The status of the school shark fishery in southeastern Australian waters. Aust. J. Mar. Freshw. Res., 10: $150-176$.

1990. School shark tagging program 1947-1956. Safish 15(1): 5-8.

PRINCE, J. D. 1992. Stock assessment and fisheries management in the southern shark fishery: an independent perspective. Australian Fisheries Management Authority, Canberra. SharkFAG Doc., No. SharkFAG/99/D17, 23 p.

PUNT, A. E. 2000. Do survey data for gummy shark (Mustelus antarcticus) provide evidence for non-uniform availability? SharkFAG Doc., No. SharkFAG/00/D10.

PUNT, A. E., and T. I. WALKER. 1998. Stock assessment and risk analysis for the school shark (Galeorhinus galeus) off southern Australia. Mar. Freshw. Res., 49: 719-731.

PUNT, A. E., F. PRIBAC, T. I. WALKER, B. L. TAYLOR, and J. D. PRINCE. 2000. Stock assessment of school shark, Galeorhinus galeus, based on a spatially explicit population dynamics model. Mar. Freshw. Res., 51: 205-220.

PUNT, A. E., F. PRIBAC, T. I. WALKER, and B. L. TAYLOR. 2001. Population modelling and harvest strategy evaluation for school and gummy shark. Final Report for Fisheries Research and Development Corporation Project 99/102. CSIRO Marine Research.

SIMPFENDORFER, C. A. 1999. Demographic analysis of the dusky shark fishery in southwestern Australia. Am. Fish. 
Soc. Symp., 23: 149-160.

STEVENS, J. D., T. T. WALKER, and C. A. SIMPFENDORFER. 1997. Are southern Australian shark fisheries sustainable? In: Developing and Sustaining World Fisheries Resources: the State of Science and Management. Second World Fisheries Congress. 28 July-2 August 1996, Brisbane. D. A. Hancock, D. C. Smith, A. Grant, and J. P. Beumer (eds.) CSIRO Publishing: Melbourne. p. 62-66.
WALKER, T. I., P. L. MOULTON, N. G. DOW, and N. R. SADDLER 1989. Southern Shark Assessment Project Final FIRTA Report: March 1989. Victorian Dept. Conservation, Forests and Lands, Fish. Div. Inter. Rep., No. 175b, p. $1-24$.

WALKER, T. I. 1998. Can shark resources be harvested sustainably? A question revisited with a review of shark fisheries. Mar. Freshw. Res., 49: 553-572. 